\title{
Takotsubo syndrome: a neurocardiac syndrome inside the autonomic nervous system
}

\author{
Vincenzo Marafioti ${ }^{1}$ (D) $\cdot$ Giovanni Benfari ${ }^{1}$
}

Published online: 20 October 2018

(C) Springer Science+Business Media, LLC, part of Springer Nature 2018

We really enjoyed reading the review by Dr. Borodzicz et al. [1], on the role of the autonomic sympathetic nervous system (ANS) in takotsubo syndrome (TTS). We would appreciate the comment of the authors on the two following issues: (1) Although they elegantly suggested the essential role of ANS in the pathophysiology of TTS, no details have been provided regarding the neuronal alterations in the brain regions involved in the modulation of the sympathetic nervous system. The cardiovascular function is regulated by a complex network of cortical, subcortical, and peripheral areas with hierarchical distribution. A key role in this circuitry is played by the insular cortex (IC), a strategic area of the brain highly connected with the cerebral cortex, basal nuclei, amygdaloid body, limbic areas, and the dorsal thalamus [2]. The IC may indicate how an emotional or a physical stressor trigger, reported in more than two thirds of patients with TTS, alter cardiac autonomic tone. In this respect, the mentioned study by Klein et al. [3] supporting a heart-brain interaction in the pathogenesis of TTS, highlights the critical role of the IC in regulating top-down autonomic responses. (2) It is surprising that left ventricular (LV) apical ballooning during systole in TTS with unknown mechanism is accepted as typical but without argumentum so far. Of note, the circumferential pattern of ventricular wall motion abnormalities is congruent with cardiac nerve distribution mapped by Antonio Scarpa acclaimed anatomist and neurologist [4]. For the first time in history, he showed that the terminal ramifications of the cardiac nerves were directly connected to the muscle fibers of the heart. The efferent neural ramifications of cardiac plexuses illustrated in his greatest work, Tabulae neurologicae ad illustrandam historiam cardiacorum nervorum [5] are curiously adjacent to areas of regional LV dysfunction in TTS.
Individual differences in the anatomy of cardiac sympathetic innervation might explain the anatomical variants (basal and mid ventricular). We agree with the authors on the essential role of ANS in the pathophysiology of TTS and we should not forget that the heart is not only made by muscle and vessels, but it is also a fascinating compound of nerves. This little brain in the heart may explain the mystery of neurocardiac syndrome like TTS.

\section{Compliance with ethical standards}

Conflicts of interest The authors declare no potential conflicts of interest.

\section{References}

1. Borodzicz S, Czarzasta K, Opolski G, Cudnoch-Jędrzejewska A (2018) Autonomic nervous system in Takotsubo syndrome. Heart Fail Rev. https://doi.org/10.1007/s10741-018-9729-5

2. Oppenheimer S, Cechetto D (2016) The insular cortex and the regulation of cardiac function. Compr Physiol 6(2):1081-1133

3. Klein C, Hiestand T, Ghadri JR, Templin C, Jäncke L, Hänggi J (2017) Takotsubo syndrome-predictable from brain imaging data. Sci Rep 7(1):5434

4. Marafioti V, Turri G, Carbone V, Monaco S (2018) Association of prolonged QTc interval with takotsubo cardiomyopathy: a neurocardiac syndrome inside the mystery of the insula of Reil. Clin Cardiol 41:551-555

5. Scarpa A (1794) Tabulae neurologicae ad illustrandam historiam anatomicam, cardiacorum nervorum, noni nervorum cerebri, glossopharyngaei, et pharyngaei ex octavo cerebri. Balthasarem Comini, Pavia

Vincenzo Marafioti

vincenzo.marafioti@fastwebnet.it

1 Cardiovascular and Thoracic Department, University Hospital of Verona, P. Stefani 1, 37126 Verona, Italy 